\title{
Acoustic emission monitoring and damage mode discrimination of APS thermal barrier coatings under high temperature CMAS corrosion
}

L. Yang ${ }^{\mathrm{a}, \mathrm{b}, *}$, T.T. Yang ${ }^{\mathrm{a}, \mathrm{b}}$, Y.C. Zhou ${ }^{\mathrm{a}, \mathrm{b}, *}$, Y.G. Wei ${ }^{\mathrm{c}}$, R.T. Wu ${ }^{\mathrm{d}}$, N.G. Wang ${ }^{\mathrm{a}, \mathrm{b}}$

${ }^{a}$ Key Laboratory of Key Film Materials E Application for Equipment (Hunan province), School of Materials Science and Engineering, Xiangtan University, Xiangtan, Hunan 411105, China

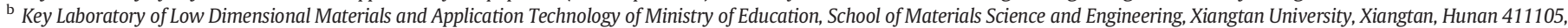

China

c LNM, Institute of Mechanics, Chinese Academy of Sciences, Beijing 100190, China

d National Institute for Materials Science, 1-1 Namiki, Tsukuba, Ibaraki 305-0044, Japan

\section{A R T I C L E I N F O}

\section{Article history:}

Received 12 April 2016

Revised 24 June 2016

Accepted in revised form 29 June 2016

Available online 30 June 2016

\section{Keywords:}

Thermal barrier coatings

Acoustic emission

Wavelet packet transform

CMAS corrosion

Damage mode

\begin{abstract}
A B S T R A C T
Molten calcium-magnesium-alumino-silicate (CMAS) corrosion is the most dangerous failure mode for thermal barrier coatings (TBCs). The real-time monitoring and mode discrimination of the corrosion failure process are desirable to understand the corrosion failure mechanism of TBCs. In this paper, the failure mechanism of the TBCs subjected to molten CMAS attack is investigated with acoustic emission (AE). Based on the number and amplitude, and compared to the substrate and the TBCs without CMAS, more serious damage is found to occur in the TBCs attacked by the molten CMAS. Possible failure modes are discriminated by wavelet analysis, and the results indicate that there are four distinct frequency bands corresponding to surface vertical cracks, sliding interface cracks, opening interface cracks, and substrate deformation in the TBCs suffered high temperature molten CMAS corrosion. In fact, the frequency band of sliding interface crack is associated with two crack types, including the crack at the YSZ/BC interface and the parallel crack in the ceramic coating induced by the compressive stress. These two cracks dominate the whole failure process, and ultimately result in the spallation of coatings.
\end{abstract}

(c) 2016 Elsevier B.V. All rights reserved.

\section{Introduction}

Thermal barrier coatings (TBCs) have been regarded as an effective approach to protect the hot-section components in the aeroengine from high temperature gas, thus leading to an enhancement in the engine efficiency [1,2]. Moreover, further increases in the thrust weight ratio and durability of the aeroengine also rely on the improvement in the TBCs $[2,3]$. The TBCs are typically comprised of four layers, i.e., a YSZ ceramic coating ( $7 \mathrm{wt} \% \mathrm{Y}_{2} \mathrm{O}_{3}$ partially stabilized $\mathrm{ZrO}_{2}$ ), an oxidation resistant metallic bond coating (NiCoCrAlY), a thermally grown oxide (TGO) layer (predominately $\alpha-\mathrm{Al}_{2} \mathrm{O}_{3}$ ) formed at the YSZ/bond coating interface, and a metallic substrate [2,4]. This complexity and diversity in the TBCs structures along with the harsh operating conditions make it difficult to predict their spallation failure, which severely shortens the service life and restricts the wide applications [4]. Hence, the failure of TBCs is a key problem and needs to be resolved urgently.

Generally, interface oxidation, erosion caused by the exotic particles, and corrosion induced by the molten $\mathrm{CaO}-\mathrm{MgO}-\mathrm{Al}_{2} \mathrm{O}_{3}-\mathrm{SiO}_{2}$ (CMAS) are regarded as three key factors leading to the failure of TBCs [4-7]. The

\footnotetext{
* Corresponding authors at: Key Laboratory of Key Film Materials \& Application for Equipment (Hunan province), School of Materials Science and Engineering, Xiangtan University, Xiangtan, Hunan 411105, China.

E-mail addresses: lyang@xtu.edu.cn (L. Yang), zhouyc@xtu.edu.cn (Y.C. Zhou).
}

third two issues have been investigated systematically [5,6,8], whereas the third one still needs to be further understood [7]. It is considered that the molten CMAS results from the ingestion of siliceous minerals (dust, sand, and volcanic ash) within the intake air during flight [7,9, 10]. At the temperature higher than $1240^{\circ} \mathrm{C}, \mathrm{CMAS}$ yields glassy melts and penetrates in the TBCs with porous microstructures (inter-columnar gaps, pores, and cracks), thus changing the near-surface mechanical properties and enhancing the spalling tendency $[9,11,12]$.

Until recently, the great effort has been made to clarify the failure mechanism of the TBCs attacked by the molten CMAS. For example, Levi et al. [7] demonstrated that the YSZ coating partially dissolved in the CMAS, leading to the phase transformation from tetragonal phase to monoclinic phase at the interface between CMAS and YSZ. Drexler et al. [13] found that anorthite $\left(\mathrm{CaAl}_{2} \mathrm{Si}_{2} \mathrm{O}_{8}\right)$ formed in the TBCs during the cooling process after CMAS corrosion, resulting in the loss of strain tolerance and failure of the coating. Mercer et al. [14] constructed a model describing the spalling depth of TBCs, and predicted that this depth is half of the critical depth for CMAS infiltration during the cold shock. However, the above researches are only based on the analysis of phase transformation, chemical composition, and infiltration thickness of the TBCs suffered from CMAS attack. They cannot provide the direct failure information, such as the failure time, mode, and microstructure evolution of the coating. Hence, a real-time nondestructive evaluation is necessary for understanding the failure mechanism of the TBCs. 
A number of approaches have been developed for the nondestructive testing and lifetime prediction of the TBCs, including acoustic emission, X-ray diffraction, thermal imaging technology, and impedance spectroscopy [15-18]. Among these, AE technique is usually adopted to identify the evolution of internal and external damage prior to failure in structural and functional materials under loading [19]. Many studies have demonstrated that $\mathrm{AE}$ characteristic signals correlate with the mechanisms and modes of coating failure. Ma et al. [20,21] used an inversion processing of $\mathrm{AE}$ signals to identify the damage sources and classify the cracking modes of plasma sprayed TBCs during four-point bend tests. Trunova et al. [22] reported the degradation evolution and failure mechanisms of TBCs during thermal cycling by analyzing microstructures and AE signals. Yang et al. [23] investigated the thermal fracture behavior of TBCs under cyclic heating and cooling, and analyzed the correlation between damage evolution in the TBCs and AE characteristic signals. All these results provide theoretical and technical support for studying the failure mechanisms of the TBCs subjected to CMAS corrosion using $\mathrm{AE}$ technique. In this paper, the failure behavior of TBCs attacked by the molten CMAS is investigated via AE technique. The aim of this paper is to analyze the failure mode of the TBCs and investigate the evolution of micro-cracks in the coating.

\section{Experimental procedure}

\subsection{Preparation of TBC specimens and CMAS glass}

During the preparation of TBCs specimen, the Ni-based superalloy (DZ125) was used as the substrate, on which a Ni-22 wt.\% Cr-7 wt.\% Al-0.2 wt.\% Y bond coat ( $100 \mu \mathrm{m})$ and a $\mathrm{ZrO}_{2}-8$ wt.\% $\mathrm{Y}_{2} \mathrm{O}_{3}$ top ceramic coating $(200 \mu \mathrm{m})$ were deposited by vacuum and air plasma spraying (APS), respectively. The TBCs specimen with the dimension of $15 \mathrm{~mm} \times 10 \mathrm{~mm} \times 3 \mathrm{~mm}$ were ultrasonically cleaned at the beginning of high temperature tests. The chemical composition of the CMAS was 48.5 wt.\% $\mathrm{SiO}_{2}-11.8$ wt.\% $\mathrm{Al}_{2} \mathrm{O}_{3}-33.2$ wt.\% $\mathrm{CaO}-6.5$ wt.\% $\mathrm{MgO}$, which is similar to those used in other studies [24]. The CMAS glass was prepared by milling the mixture of reagent grade fine powders of individual oxides $\left(\mathrm{CaO}, \mathrm{MgO}, \mathrm{Al}_{2} \mathrm{O}_{3}\right.$ and $\mathrm{SiO}_{2}$ ), then mixed with the absolute ethyl alcohol and subsequently pasted to the surface of the TBCs with an area density of $13 \mathrm{mg} / \mathrm{cm}^{2}$.

\subsection{Experiment of high temperature CMAS corrosion}

Since the actual operating environment of a gas-turbine engine had appropriate temperature-gradient (i.e., substrate is colder than the TBCs) [25], the experiments of high temperature CMAS corrosion was done in a gradient furnace and monitored with $\mathrm{AE}$, as shown in Fig. 1. For the TBCs samples, the surfaces of ceramic coatings were heated in the gradient furnace and the metal substrates were cooled by the compressed air. The samples were heated up to $1250^{\circ} \mathrm{C}$ for $30 \mathrm{~min}$ and held at this temperature for $2 \mathrm{~h}$, then cooled down to $100{ }^{\circ} \mathrm{C}$ within the furnace. The temperature data was detected by thermocouples and recorded by a computer were shown in Fig. 1. The cross sections of TBCs specimens after CMAS corrosion were observed with scanning electron microscopy (SEM) using back-scattered electron (BSE) imaging. For this observation, each TBCs sample was embedded in epoxy resin and its cross sections was ground with different grades of SiC abrasive papers and then polished using diamond paste.

\subsection{Acoustic emission monitoring}

The experimental process was monitored in real time with an $\mathrm{AE}$ measurement system (PCI-2). During this monitoring, the pre-amplifier was set as $40 \mathrm{~dB}$ and the threshold amplitude was specified at $40 \mathrm{~dB}$. The sampling frequency was $2 \mathrm{MHz}$. To avoid mechanical and electromagnetic noise, the low- and high-filter frequencies were set as $0.1 \mathrm{MHz}$ and $1 \mathrm{MHz}$, respectively. As the conventional piezoelectric transducer can only be used at ambient temperature, a waveguide with the good transmission of acoustic signals (low attenuation of the signal energy) was designed using Nichrome wire to resist the chemical corrosion (oxidative or reductive atmospheres) [26]. This waveguide connects the specimen and transducer perfectly, consequently avoiding the transducer locating at high temperatures. One end of this Nichrome wire was welded onto the substrate surface, and the other was attached firmly to an AE sensor via an elastic cord and butter couplant (a kind of

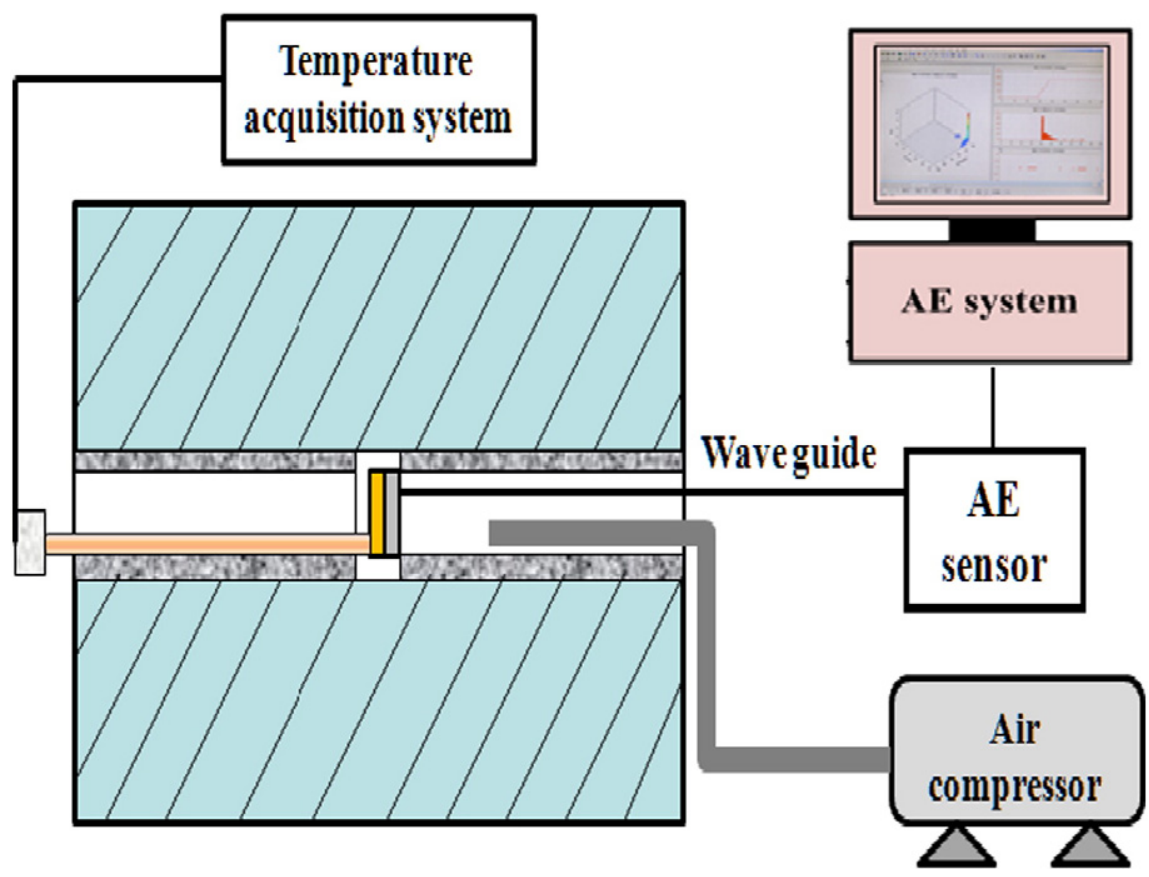

Fig. 1. Schematic diagram of the test and $\mathrm{AE}$ monitoring. 
coupling medium). The waveguide can therefore keep the AE sensor operating at ambient temperature and monitor the high temperature tests.

\section{Results and discussion}

\subsection{Acoustic emission characteristics of TBCs under CMAS corrosion}

The AE event counts recorded from the TBCs samples with and without CMAS, along with the substrate exposed at high temperature are shown in Fig. 2. The red and violet lines denote the temperature at the surface and back of the sample, respectively. The AE events apparently increase with increasing temperature until the temperature at the surface rise to $1250{ }^{\circ} \mathrm{C}(\mathrm{I})$. After that, the $\mathrm{AE}$ events enter into a constant value for the samples without CMAS (II), whereas the CMAS interaction leads to a slow increase in the number of AE events (II). In the cooling stage (III), the AE events increase quickly. The variation trends of the three parallel experiments exhibit similarity with prolonging time. The AE events of TBCs specimens without CMAS are basically consistent with those of the substrate during heating and holding period, indicating that the AE signals are mainly related to the substrate at this time. However, these AE signals increase quickly during cooling period owing to the failure of ceramic coating. In addition, the AE events of the TBCs specimen with CMAS are significantly more than other samples throughout the whole experiment, indicating that the molten CMAS attacks the TBCs during the holding period and the thermal mismatch between CMAS and ceramic coating occurs during the cooling period. From the above analysis, it is evident that CMAS corrosion will cause more damage in the ceramic coating. Each experimental testing is repeated three times. The result indicates that the trends of AE signals are similar.

Fig. 3 shows the amplitude distributions of three samples. It can be seen that the AE amplitudes during the heating (I) and holding (II) periods mainly distribute in a range of $40-70 \mathrm{~dB}$. The amplitudes of TBCs specimens mainly appear at $40-100 \mathrm{~dB}$ during cooling, whereas the amplitudes of the substrate locate at $40-70 \mathrm{~dB}$ (Fig. 3(c)). In addition, there are many signals exceeding $80 \mathrm{~dB}$ in the TBCs sample with CMAS during cooling stage (Fig. 3(a)). It has been proved that the signals of high amplitude and energy are related to the spallation of the coatings [27], suggesting that CMAS corrosion could cause a more serious damage in the TBCs. However, other analysis methods are still necessary because the comparison of $\mathrm{AE}$ amplitudes throughout the experiment is an unreliable method of discriminating the mode of coating damage.

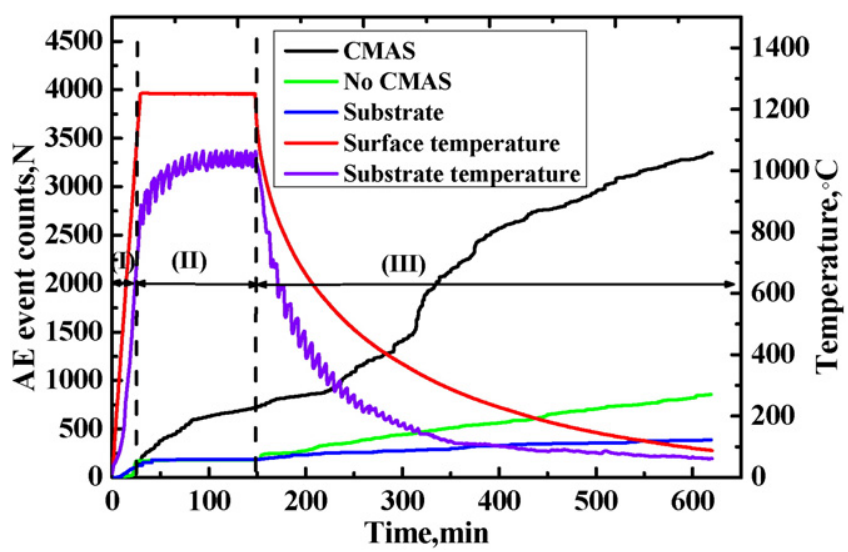

Fig. 2. AE event counts for the process of TBCs under high temperature test. I, II and III regions between the vertical dotted lines represent the heating, holding, and cooling stages, respectively.
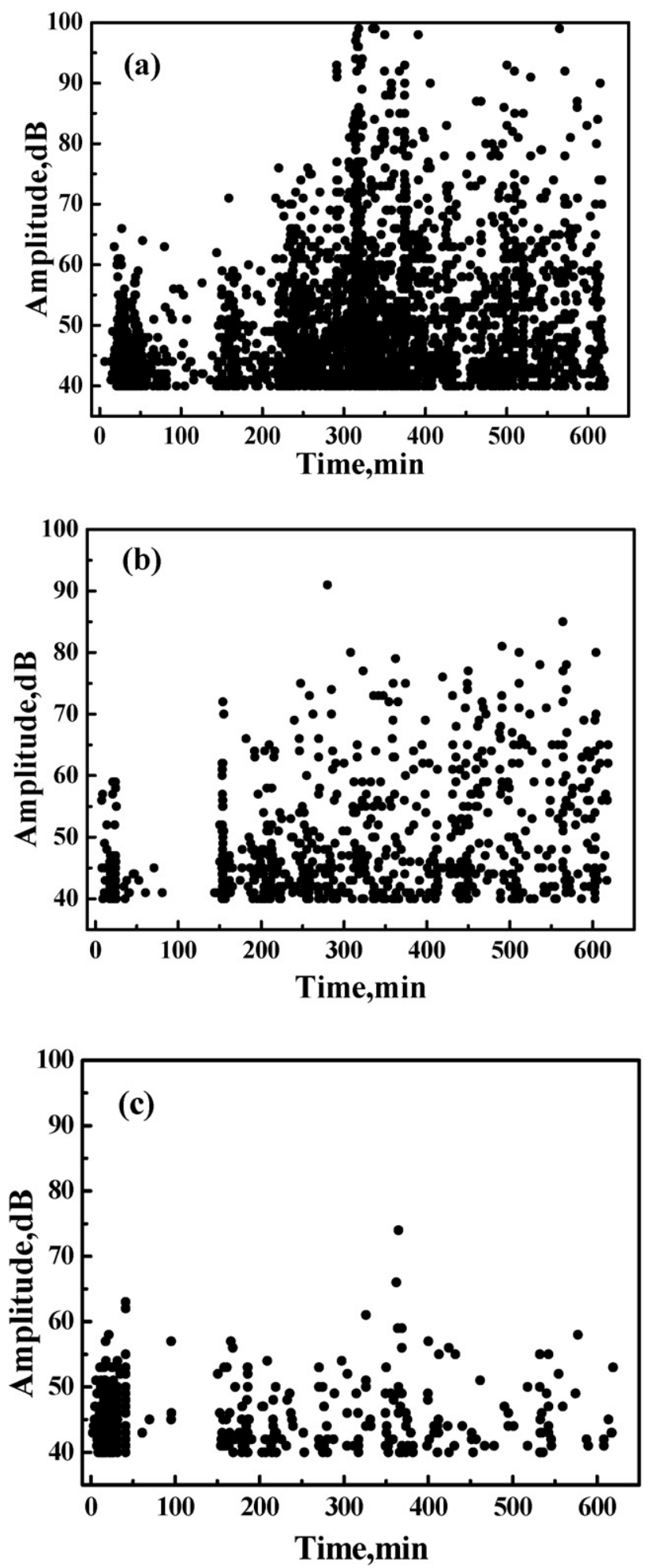

Fig. 3. Amplitude distribution of the AE signals for (a) TBCs with CMAS, (b) TBCs without CMAS, and (c) substrate.

\subsection{Discrimination of the damage modes for the TBCs under high tempera- ture CMAS corrosion}

The frequency spectrum analysis is a common method used for $\mathrm{AE}$ signal processing. This method transforms the AE signals from time domain to frequency domain, and extracts the message reflecting the $\mathrm{AE}$ source [28]. The frequency spectrum of $\mathrm{AE}$ signals are strongly 
dependent on the failure modes of materials, but are almost independent of the failure size and operating pressure [23,28]. Previous studies indicated that the surface vertical cracks, sliding interface cracks, and opening interface cracks correspond to the characteristic frequency bands of $0.20-0.25 \mathrm{MHz}, 0.25-0.32 \mathrm{MHz}$, and $0.4-0.45 \mathrm{MHz}$,
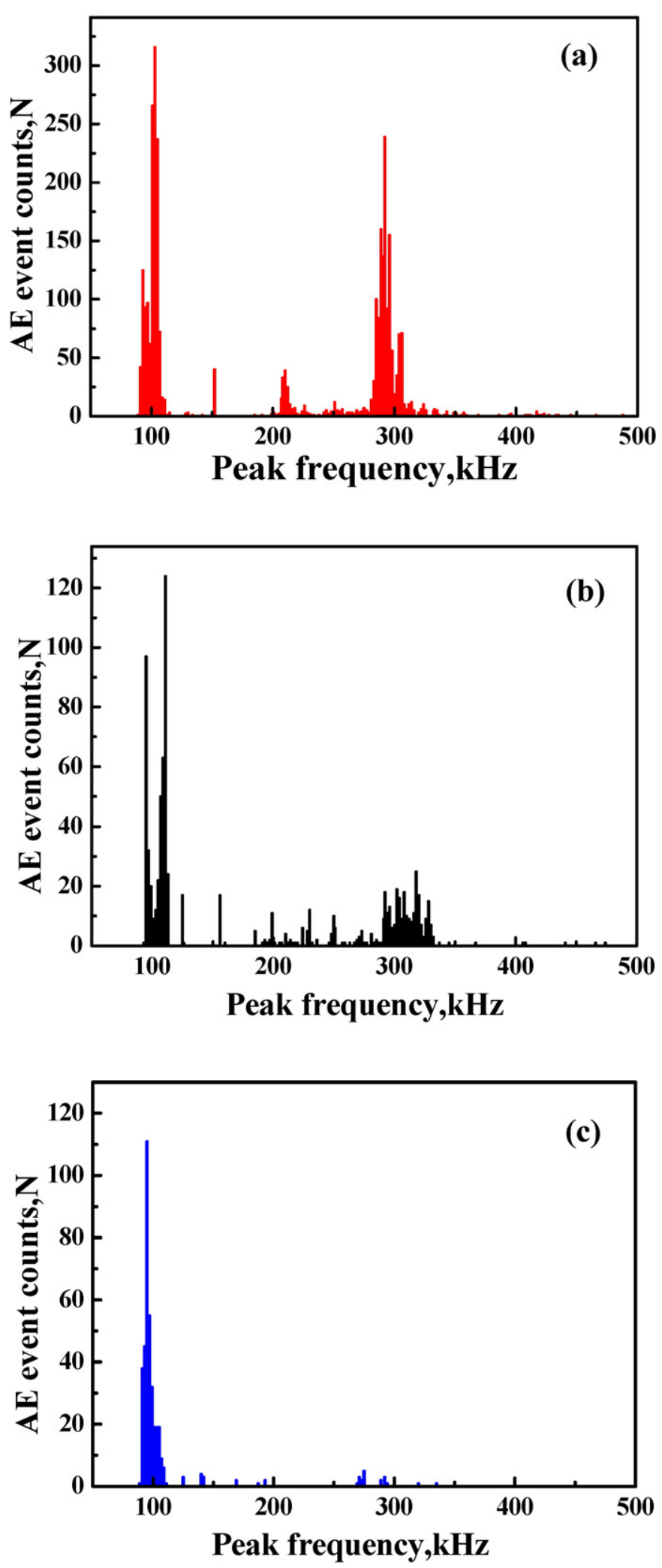

Fig. 4. Histogram of the peak frequencies for the TBCs under high temperature test: (a) TBCs with CMAS, (b) TBCs without CMAS, and (c) substrate. respectively $[16,23,28,29]$. After the statistical analysis on the characteristic peak frequency of AE signals, we also found three similar frequency bands for surface vertical cracks, sliding interface cracks, and opening interface cracks (Fig. 4). The typical waveform and frequency spectrum of these three cracks are shown in Fig. 5(a), (b), and (c), with the peak points locating at $0.21 \mathrm{MHz}, 0.29 \mathrm{MHz}$, and $0.41 \mathrm{MHz}$, respectively. From Fig. 5(c) we know that the frequency range of substrate is 0.09$0.13 \mathrm{MHz}$. The typical waveform and frequency spectrum is shown in Fig. 5(d), with a peak frequency of $0.09 \mathrm{MHz}$. This result is different from that of previous research, attributed to the different substrate material for tests [16,29]. In addition, there are still a few signals between 0.13 and $0.16 \mathrm{MHz}$, with the peak frequency locating at $0.15 \mathrm{MHz}$. This is a typical continuous signal caused by the metal substrate, as shown in Fig. 5(e), even though the waveform and frequency spectrum are obviously different from the signals in Fig. 5(d). Considering that the kind of signals has nothing to do with the damage modes in the ceramic coating, further concrete analysis is unnecessary here.

The SEM is used to examine the cross section of the TBCs sample subjected to CMAS attack. The substrate and TBCs specimen without CMAS corrosion were used for comparison, as shown in Fig. 6. It can be observed from Fig. 6(b) that surface vertical cracks appear at the surface and extend partially through the ceramic coating. Similarly, interface cracks appear at the YSZ/BC interface (Fig. 6(c)). According to the SEM images in Fig. 6(a) and (b), many parallel cracks can be seen in the ceramic coating of the TBCs specimen with CMAS, however, the corresponding frequency band was not found from the previous analysis. In contrast, parallel cracks can hardly be observed in the TBCs sample without CMAS (Fig. 6(d)). On the other hand, the number of AE signals for the sliding interface cracks in the TBCs sample with CMAS are obviously higher than those of the specimen without CMAS, as shown in Fig. 4(a) and (b). This phenomenon might be due to the fact that most of the interface cracks mainly locate at the ceramic layer near the YSZ/BC interface. These results imply that the frequency band of sliding interface cracks should include the cracks between the YSZ/BC interface and the parallel cracks in the TBCs.

Nevertheless, the modulation of dominant frequency and the lack of information on the time dominant make it difficult and unreliable for the discrimination of AE signals when only the frequency spectrum analysis is used [29]. Besides, it is time- consuming and inconvenient to deal with each signal in this way. As a consequence, the wavelet analysis is applied to further analyze and identify the damage modes, because this analysis has good resolution in time and frequency domain for non- stationary random signals [23,29]. In wavelet analysis, a signal is divided into detail and approximate signal, the former is high-frequency components of the signal and the latter is the low-frequency part. If only the approximate signal is then divided into a next level of approximate and detail signals, it will be called as the discrete wavelet transform [30]. However, wavelet packet transform is more delicate than discrete wavelet transform for signal analysis, because the former handles with the low and high frequency components of signals at the same time [31].

In this paper, all $\mathrm{AE}$ signals are analyzed by wavelet packet transform. A given AE signal, $S(t)$, can be expressed as the summation of all wavelet packet components using the following equation:

$S(t)=\sum_{i-1}^{2 j} S_{j}^{i}(t)$

where $i=1,2,3, \ldots$, and $2^{j}$ is the decomposition level in a wavelet packet, $j$ is the scale parameter. The energy in each component is defined as:

$E_{J}^{i}(t)=\sum_{\tau=t_{0}}^{t}\left(S_{j}^{i}(\tau)\right)^{2}$ 

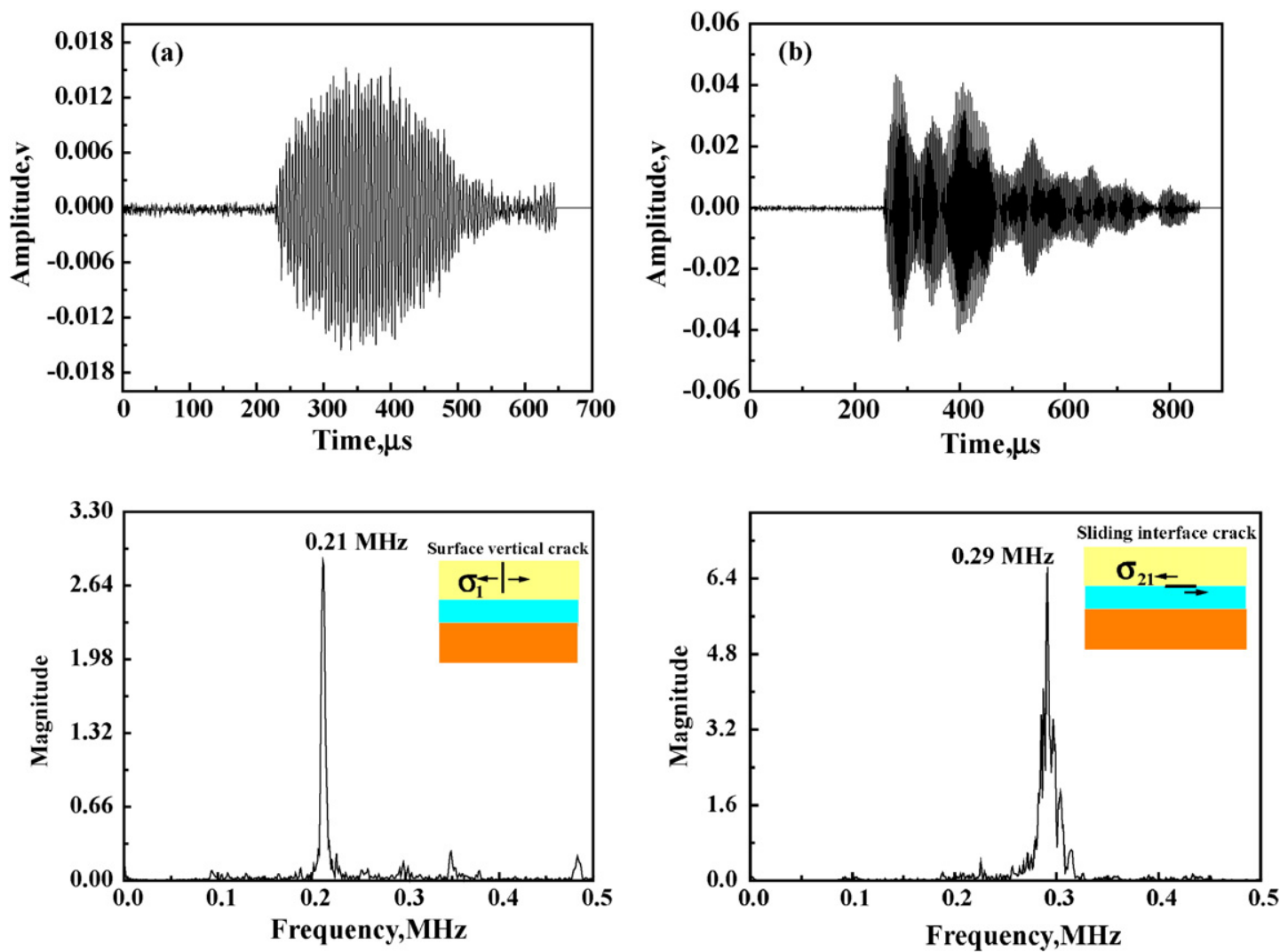

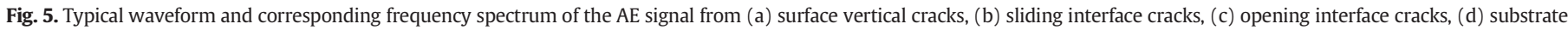
deformation, and (e) others.
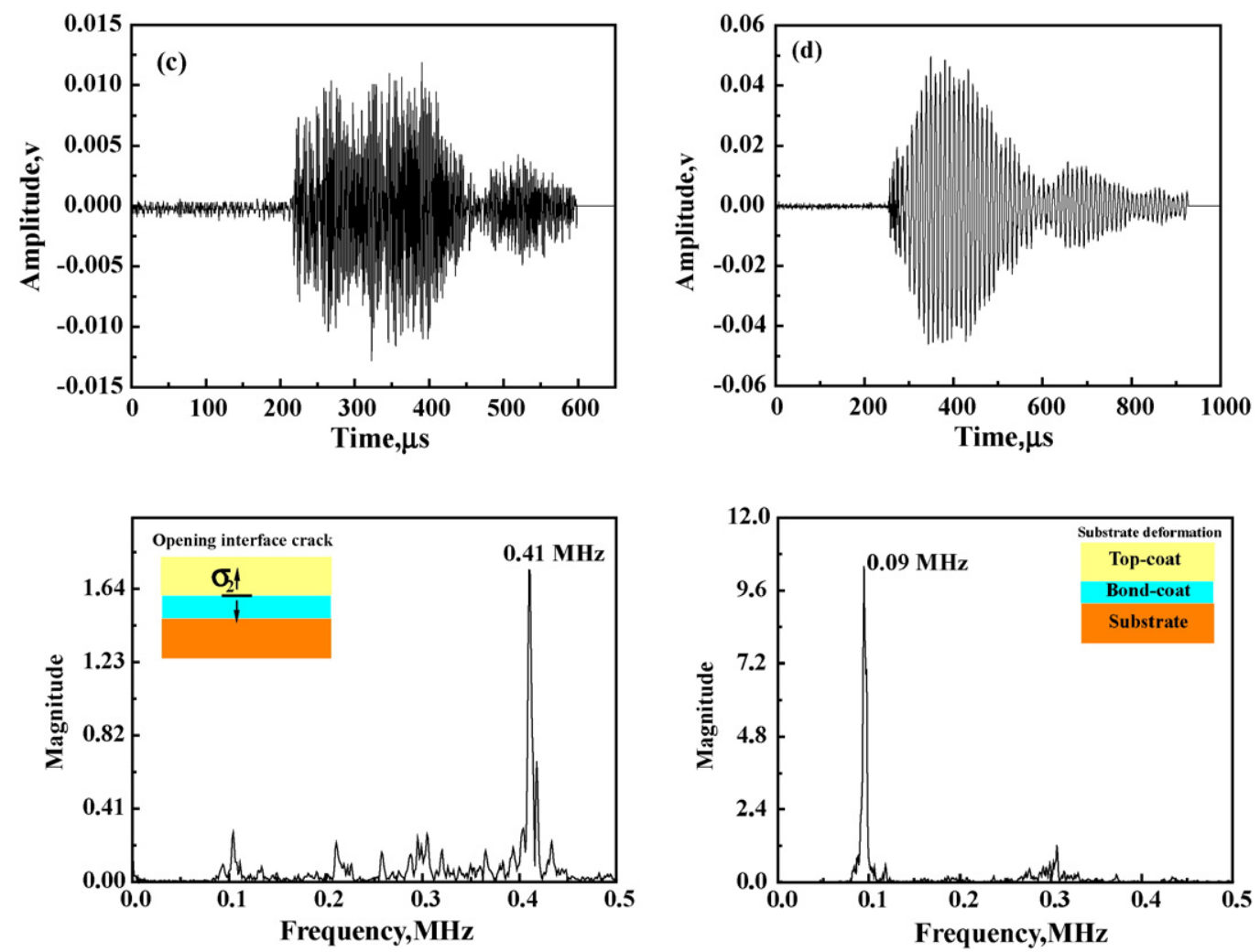

Fig. 5 (continued). 

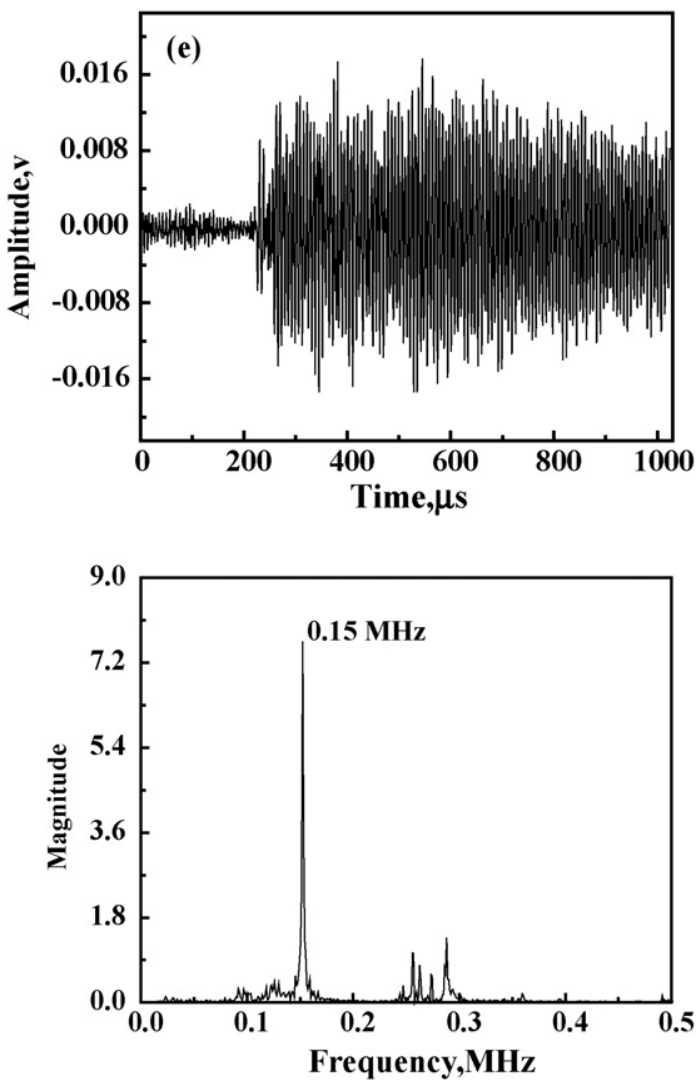

Fig. 5 (continued).
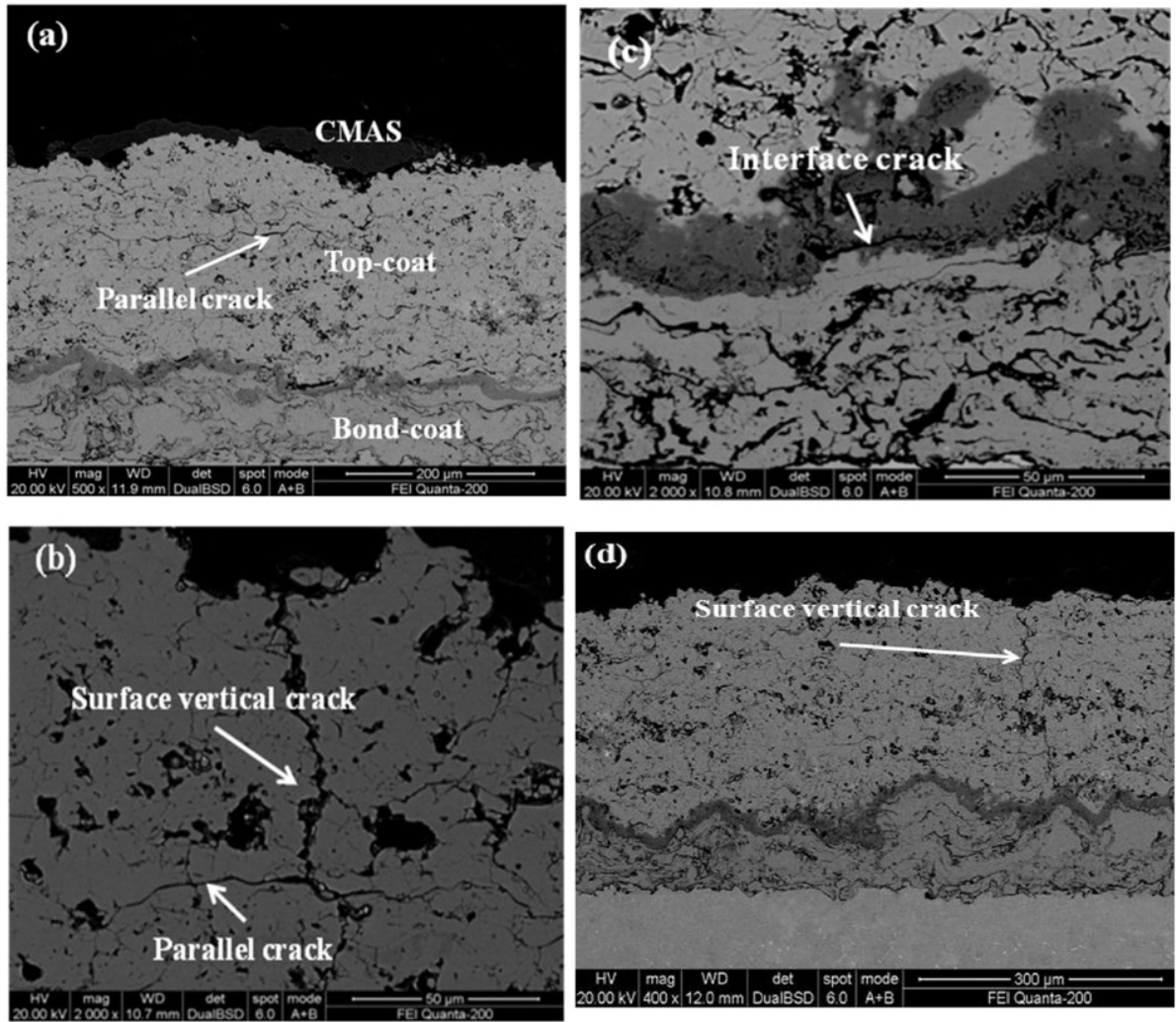

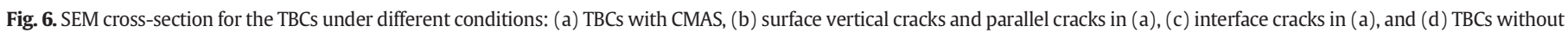
CMAS. 


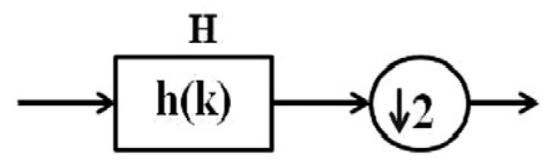

Low pass filter and decimation

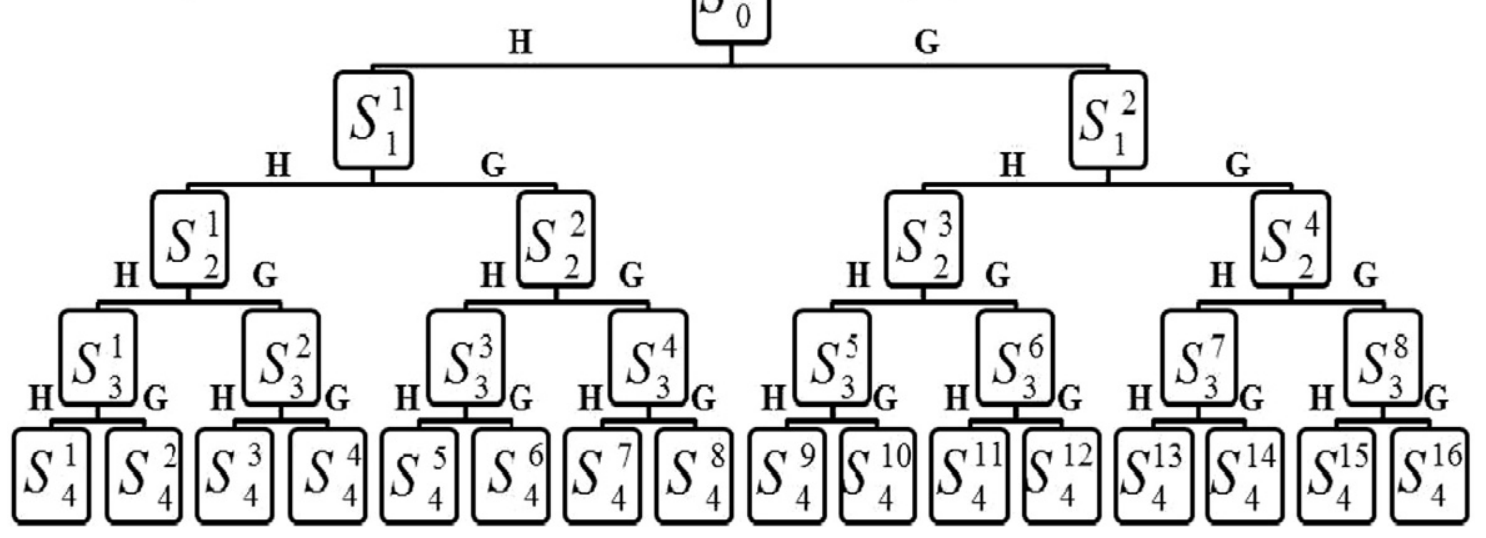

Fig. 7. Schematic diagram of wavelet packet transform with four levels.

\subsection{Fracture behavior of the TBCS under high temperature CMAS corrosion}

To analyze the fracture behavior of the TBCs under high temperature CMAS corrosion, all AE signals are imported into the Matlab software to discriminate the damage modes (Fig. 9), and obtain the damage mode differentiation results of AE signals (Fig. 10). Failures are found to mainly occur during the heating (I) and cooling (III) stages, and seldom generate during the holding period (II), as shown in Fig. 10. The substrate deformation appears at the heating period (I) and the beginning of the rapid cooling stage as shown in Fig. 10(a). Sliding interface cracks appear at the beginning of cooling period and remain active, then gradually increase. When temperature reaches $400{ }^{\circ} \mathrm{C}$, there is a dramatic climb in AE signals associated with sliding interface cracks. Meanwhile, the surface vertical cracks and opening interface cracks form. In fact, substrate deformations occur due to the thermal expansion deformation of the metal substrate. Sliding interface cracks and opening interface cracks are activated by shear stress $\sigma_{21}$ and tensile stress $\sigma_{2}$ at the YSZ/BC interface, respectively, due to the thermal expansion mismatch [29]. Surface vertical cracks mainly occur in the ceramic coating under the tensile stress $\sigma_{1}$ attributed to thermal expansion mismatch between the coating and other layers $[23,33]$. In addition, the thermal expansion coefficient of CMAS is lower than that of TBCs. The additional
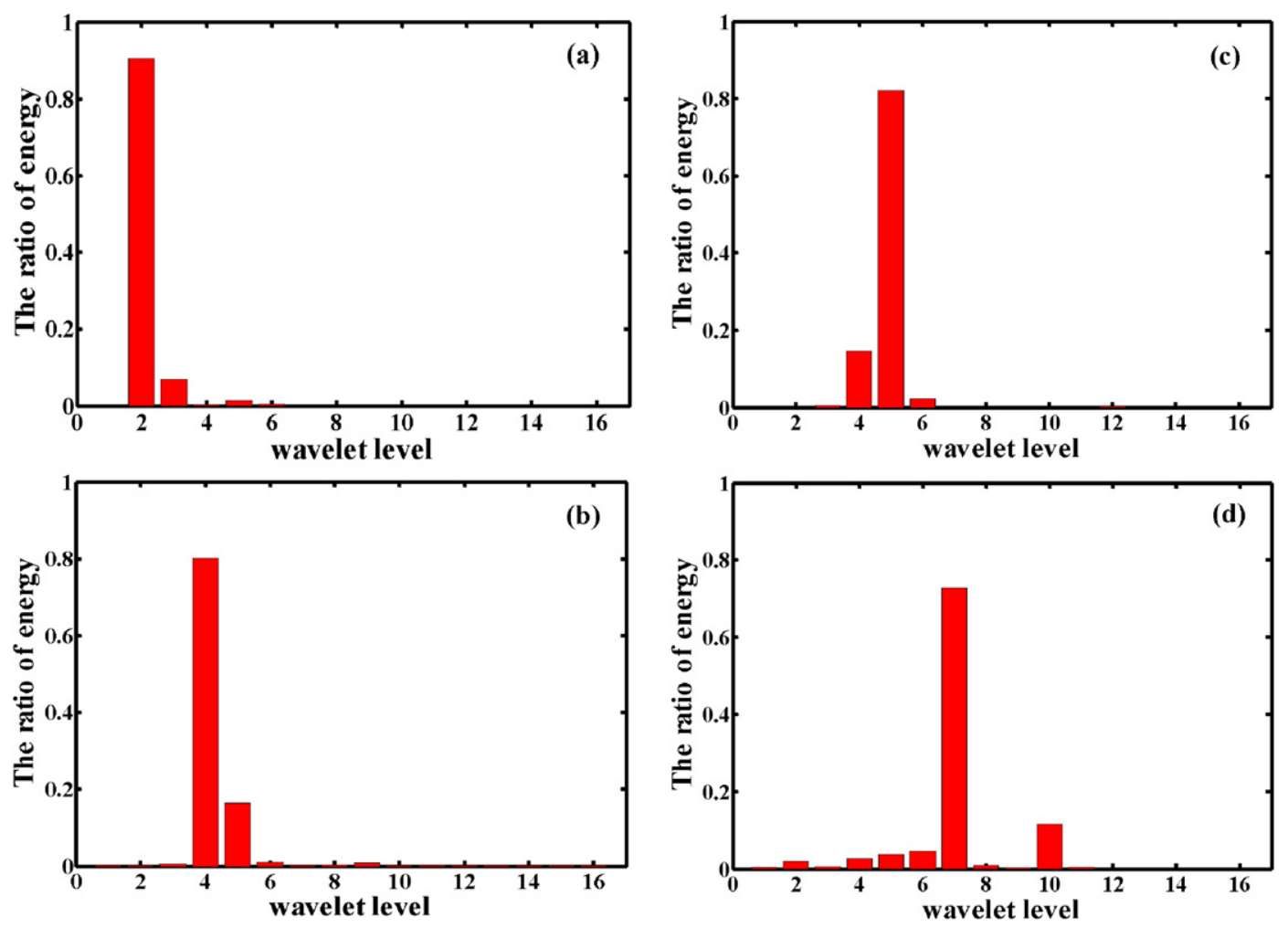

Fig. 8. Typical distribution histograms of energy coefficients for (a) substrate deformation (b) surface vertical cracks, (c) sliding interface cracks, and (d) opening interface cracks. 


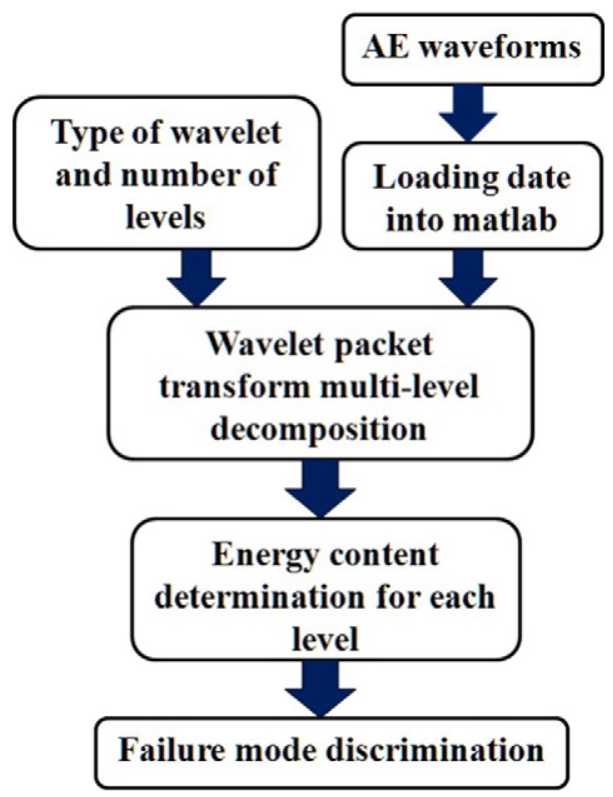

Fig. 9. The schematic diagram of AE signals analysis.

compressive stress generates in the TBCs specimen with CMAS upon cooling. This stress accumulates large enough to form parallel cracks between the CMAS penetrated and un-penetrated layers. Obviously, sliding interface cracks occur more frequently than the opening interface cracks throughout the entire test (Fig. 10(a) and (b)). This result is in agreement with the statements made by Fan et al. [34] that the crack phase angle exceeded $45^{\circ}$ in the YSZ/BC interface, indicating that the sliding interfaces are dominant. The above results demonstrate that the primary reason for failure of the TBCs attacked by CMAS is the sliding interface crack.

\subsection{Thermomechanical analysis of TBCs attacked by CMAS corrosion and delamination maps}

Evans and Hutchinson [35] developed a model to predict the delamination of the TBCs attacked by the molten CMAS with thermal gradient. Krause et al. [36] modified the above model and considered the strain during the phase transformation induced by the molten CMAS. In this paper, we use the model derived by Krause et al. to analyze the delamination in TBCs and explain the characteristics of AE signals under the condition of CMAS corrosion with temperature gradient during the cooling stage.

The strain from the phase transformation can be expressed using the following relation:

$\varepsilon_{\text {transf }}=\frac{p \Delta V}{3 V}$

where $\Delta V / V$ represents the transformation volume expansion, and its value is 0.03 [36]. $p$ is the volume fraction of $\mathrm{ZrO}_{2}$ grains that have undergone the $t \rightarrow m$ phase transformation. At the position $\mathrm{y}$, the stress $\sigma(y)$ during the cooling process is calculated using Eq. (6) [36].

$\sigma(y)=\left\{\begin{array}{l}\frac{E_{1} \alpha_{T B C} \Delta T_{\text {sur } / \text { sub }}}{(1-v)}\left\{1+\frac{y}{H}-\frac{\Delta \alpha \Delta T_{\text {sub }}+\varepsilon_{\text {trans }}}{\alpha_{T B C} \Delta T_{\text {sur } / \text { sub }}}\right\}, 0>y>-h \\ \frac{E_{2} \alpha_{T B C} \Delta T_{\text {sur } / \text { sub }}}{(1-v)}\left\{1+\frac{y}{H}-\frac{\Delta \alpha \Delta T_{\text {sub }}}{\alpha_{T B C} \Delta T_{\text {sur } / \text { sub }}}\right\},-h>y>-H\end{array}\right.$

where the initial temperature at the surface and back of the sample are $T_{\text {sur }}^{i}$ and $T_{\text {sub }}^{i}$, respectively. At any subsequent stage of the cooling stage,
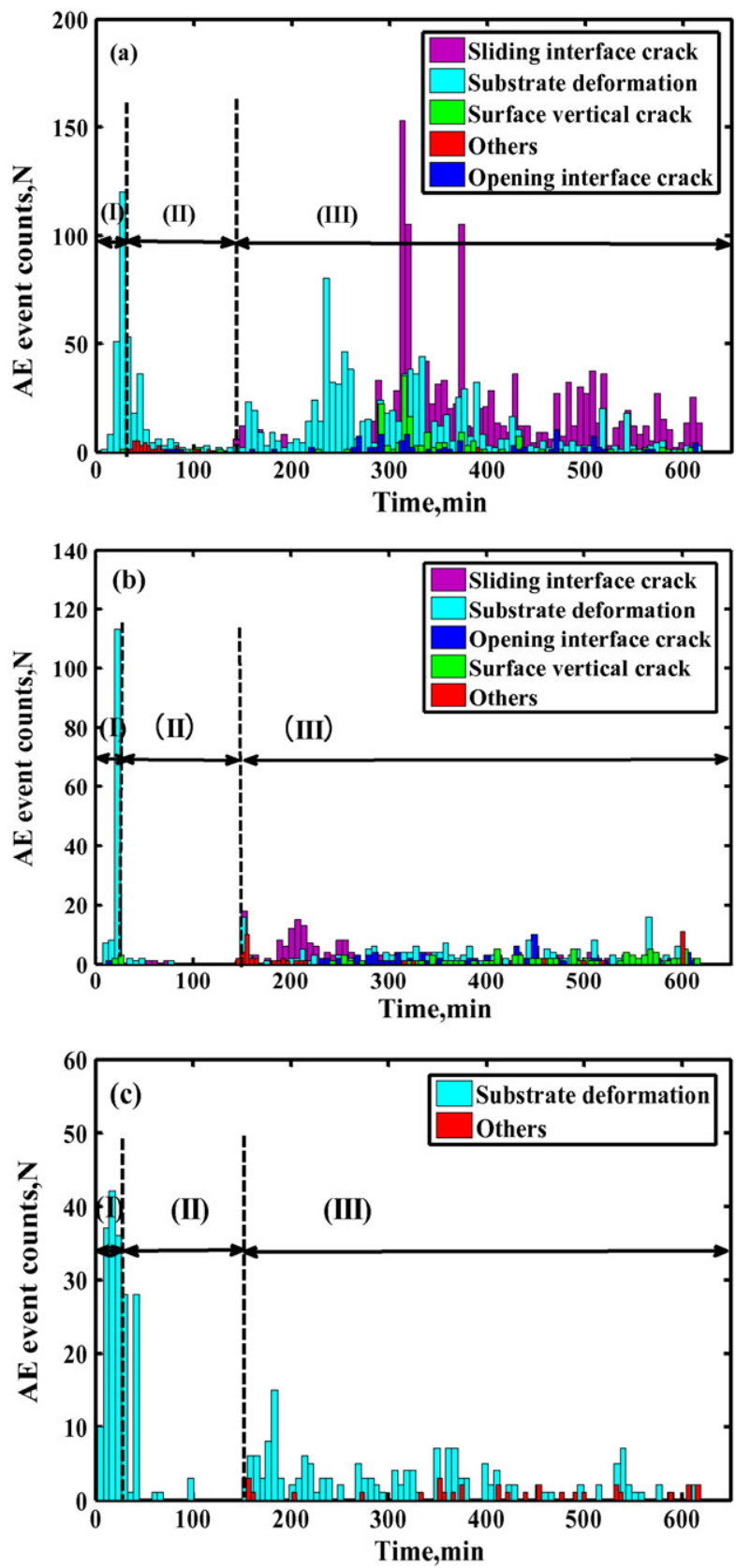

Fig. 10. The failure mode differentiation results of $A E$ signals monitored for (a) TBC with CMAS, (b) TBC without CMAS, and (c) substrate.

the temperature drop at the surface is denoted by $\Delta T_{\text {sur }}=T_{\text {sur }}^{i}-T_{\text {sur }}$ and the temperature drop at the substrate is denoted using $\Delta T_{\text {sub }}=T_{\text {sub }}^{i}-$ $T_{\text {sub }}$. The instantaneous difference of the temperature drop at the surface and substrate is $\Delta T_{\text {sur } / \text { sub }}=\Delta T_{\text {sur }}-\Delta T_{\text {sub }}$. Additionally, $\alpha_{\mathrm{TBC}}$ and $\alpha_{\text {sub }}$ are the thermal expansion coefficients of the ceramic coating and substrate, respectively. The difference of thermal expansion mismatch between substrate and coating is defined by $\Delta \alpha=\alpha_{s u b}-\alpha_{T B C}$. The coating shown in Fig. 11 has a thickness of $H$ and the CMAS penetrated layer has a thickness of $h$. The delamination at the depth of $d$ is parallel to the surface of coating. The Young's modulus of the CMAS penetrated layer(the dense layer) and the ceramic coating are given by $E_{1}$ and $E_{2}$, respectively. The Poisson's ratios $(v)$ of the penetrated layer and the coating are regarded as the same. 


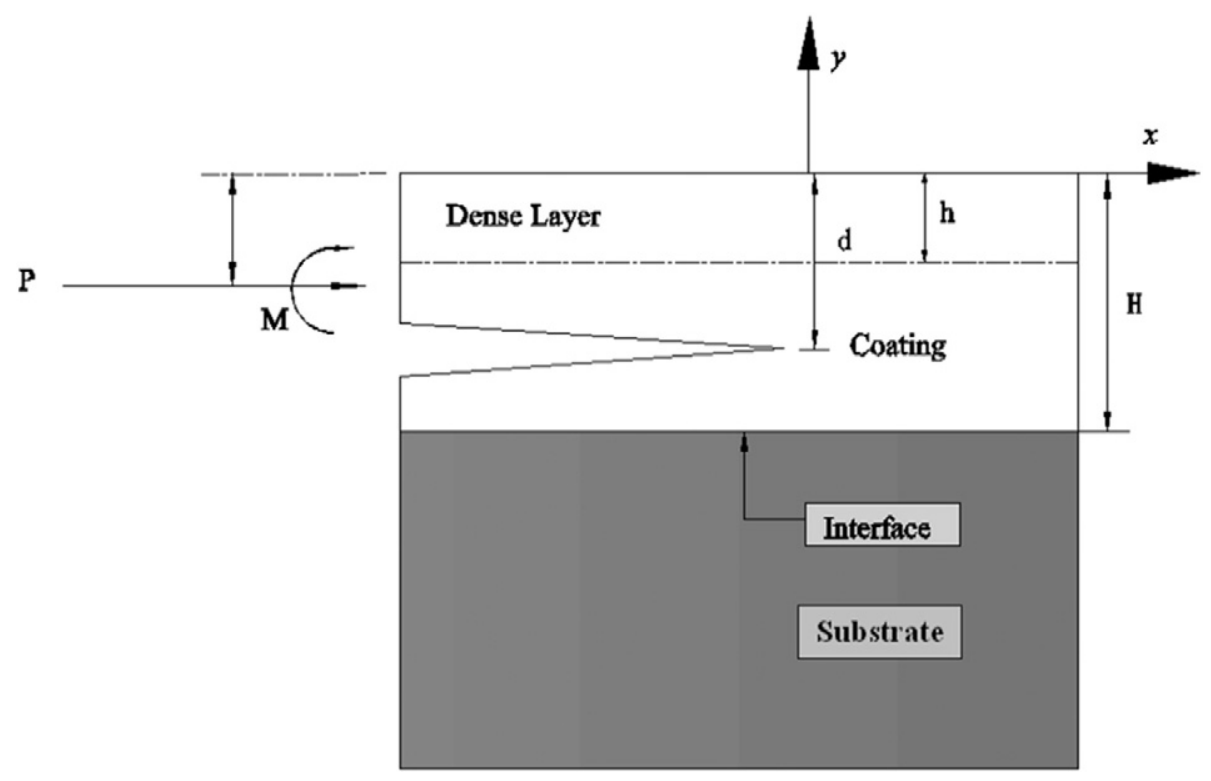

Fig. 11. A schematic of two-layer coating system identifying the parameters used in the analysis.

The force $(P)$ and the moment $(M)$ per unit length are calculated by using the stress $\sigma(y)$, which can be written as $[35,36]$

$P=\int_{-H}^{0} \sigma(y) d y$

$M=\int_{-H}^{0} \sigma(y)(D+y) d y$

where $D$ is the location of neutral bending axis. A solution for a twolayer system given by Evans and Hutchinson[35] is applied to calculate the Mode I $\left(K_{\mathrm{I}}\right)$ and Mode II $\left(K_{\mathrm{II}}\right)$ stress intensity factors:

$K_{I}=\frac{P}{\sqrt{2 A h}} \cos \omega+\frac{M}{\sqrt{2 h^{3}}} \sin \omega$

$K_{I I}=\frac{P}{\sqrt{2 A h}} \sin \omega+\frac{M}{\sqrt{2 h^{3}}} \cos \omega$

The energy release rate is given as:

$G=\frac{1}{2 \overline{E_{2}}}\left(\frac{P^{2}}{A h}+\frac{M^{2}}{I h^{3}}\right)$

where $A$ is the nondimensional effective cross section, $I$ is the moment of inertia, $\omega$ equals to $52.1^{\circ}$ [35], and $E$ is given by:

$\overline{E_{2}}=E_{2} /\left(1-v^{2}\right)$

Table 1

The material properties and other parameters used in the thermomechanical analysis of CMAS-penetrated TBCs with temperature gradient [35-37].

\begin{tabular}{|c|c|c|c|c|c|c|c|c|c|c|}
\hline $\begin{array}{l}H \\
(\mu \mathrm{m})\end{array}$ & $\begin{array}{l}h \\
(\mu \mathrm{m})\end{array}$ & $\begin{array}{l}\Gamma_{\text {sur }}^{i} \\
\left({ }^{\circ} \mathrm{C}\right)\end{array}$ & $\begin{array}{l}\Gamma_{\text {sub }}^{i} \\
\left({ }^{\circ} \mathrm{C}\right)\end{array}$ & $\begin{array}{l}E_{1} \\
(\mathrm{GPa})\end{array}$ & $\begin{array}{l}E_{2} \\
(\mathrm{GPa})\end{array}$ & $\begin{array}{l}\alpha_{T B C} \\
\left({ }^{\circ} C^{-1}\right)\end{array}$ & $\begin{array}{l}\alpha_{\text {sub }} \\
\left({ }^{\circ} \mathrm{C}^{-1}\right)\end{array}$ & $v$ & $\begin{array}{l}\Gamma_{I C}^{i} \\
\left(\mathrm{Jm}^{-2}\right)\end{array}$ & $\lambda$ \\
\hline 200 & 40 & 1250 & 1050 & 170 & 40 & $\begin{array}{l}11 \times \\
10^{-6}\end{array}$ & $\begin{array}{l}15 \times \\
10^{-6}\end{array}$ & 0.2 & 30 & 0.25 \\
\hline
\end{tabular}

Because the delamination near or at the interface is mixed-mode, the phase angle $(\psi)$ and the fracture energy $\left(\Gamma_{C}^{i}\right)$ are calculated by:

$$
\begin{aligned}
& \psi=\tan ^{-1}\left(\frac{K_{I I}}{K_{I}}\right) \\
& \Gamma_{C}^{i}=\Gamma_{I C}^{i}\left[1+\tan ^{2}((1-\lambda) \psi)\right]
\end{aligned}
$$

where $\lambda$ is the mode mix coefficient, $\Gamma_{I C}^{i}$ is the mode I fracture energy, $G=\Gamma_{C}^{i}$ is assumed to calculate the delamination boundaries for the system. The material properties and other parameters are listed in Table 1.

Fig. 12 shows the regions of TBC delamination and no-delamination for a function of $p$, while $H=200 \mu \mathrm{m}, d=200 \mu \mathrm{m}$. In addition, $h=$ $40 \mu \mathrm{m}$, which is the CMAS penetration depth [36,37]. The red dashed curve indicates an experimental cooling trajectory from $T_{\text {sur }}^{i}=1250^{\circ} \mathrm{C}$ and $T_{\text {sub }}^{i}=1050^{\circ} \mathrm{C}$ to $T_{\text {sur }}=79^{\circ} \mathrm{C}$ and $T_{\text {sur }}=61^{\circ} \mathrm{C}$. When $p$ is a constant, the no-delamination region locates between the lines with the same

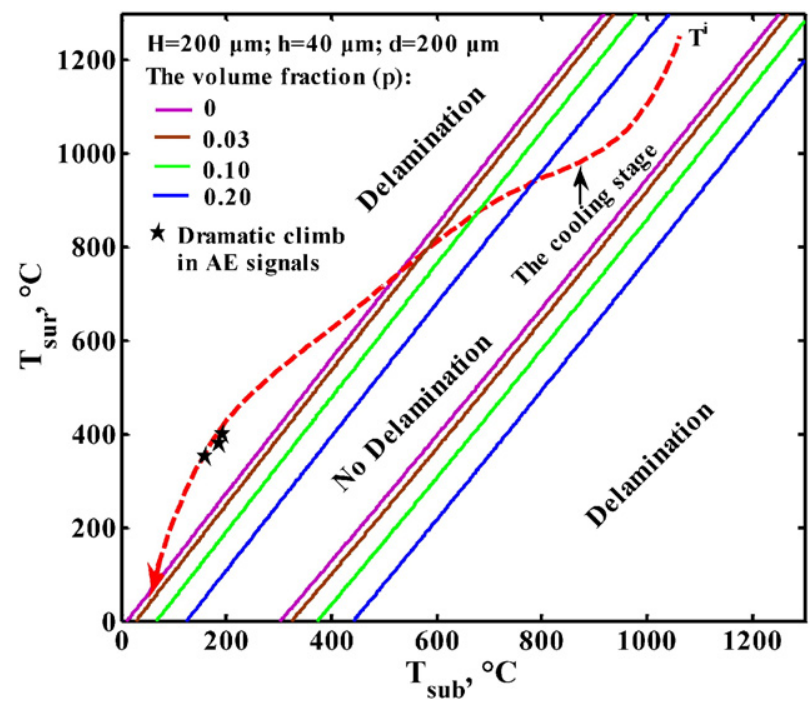

Fig. 12. Delamination maps for the system during the cooling stage described by parameters in Table 1 and $p$ is varied from 0 to 0.20 . The red dashed curve indicates a cooling trajectory from the test. The black star denotes the dramatic climb in AE signals during the test. 


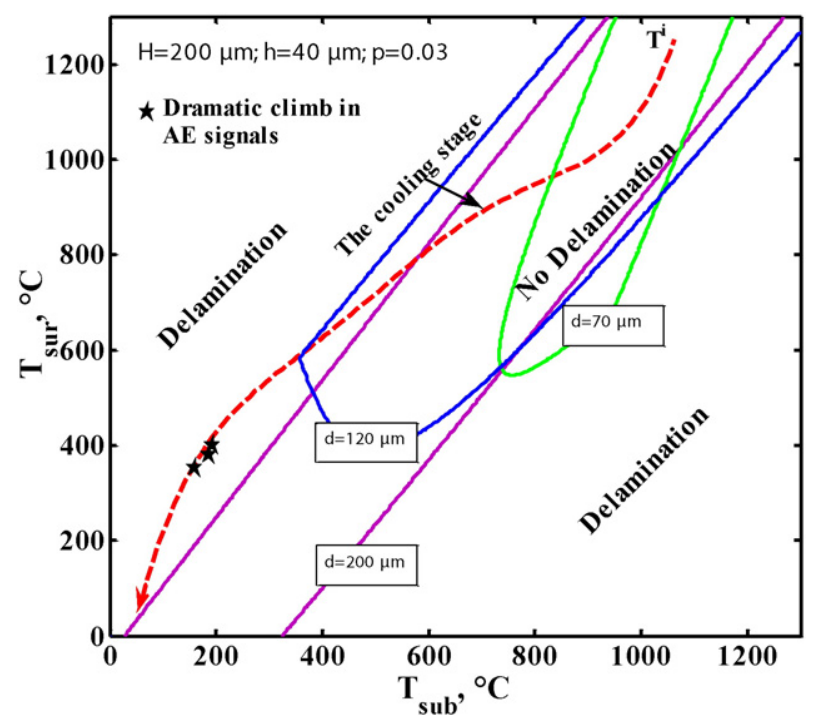

Fig. 13. Delamination maps for the system during the cooling stage described by parameters in Table 1 and $d$ is varied from 70 to $200 \mu \mathrm{m}$. The red dashed curve indicates a cooling trajectory from the test. The black star denotes the dramatic climb in AE signals during the test.

color, while other regions are the delamination regions. At the beginning of cooling, the red dashed curve locates in the region without delamination. At the subsequent stage of the cooling, the curve starts to enter the delamination region. As the value of $p$ increases, more parts of cooling curve enter into the delamination region. The effect of $p$ on the delamination indicates the importance of the phase transformation. When the surface temperature approximately drops to $400^{\circ} \mathrm{C}$, the curve crosses into the delamination region. The temperature of $400{ }^{\circ} \mathrm{C}$ has the farthest distance to the delamination boundary, indicating that the failure of TBCs is likely to occur at this moment. These black stars are in the delamination region, denoting the dramatic climb in AE signals during the test. Fig. 13 shows the results for a constant $p(=0.03)$, but with different thicknesses $(d=70-200 \mu \mathrm{m})$. The cracks firstly occur between the interface of CMAS penetrated coating and the coating without CMAS penetration or between the interface of ceramic coating and substrate during the cooling. These results indicate that the failure of TBCs mainly occur at about $400{ }^{\circ} \mathrm{C}$, the deep delamination is close to the CMAS penetrated layer or between the interface of ceramic coating and substrate.

\section{Conclusion}

In this paper, we investigate the damage behavior of the TBCs attacked by the molten CMAS using real-time AE method, and discriminate the damage modes using the wavelet analysis. The main conclusion can be drawn as follows:

(1) Based on the number and amplitude of AE signals, it is found that more serious damage occurs in the TBCs attacked by the molten CMAS, as compared to the experimental results of the substrate and TBCs specimens without CMAS.

(2) There are four distinct frequency bands in the TBCs under molten CMAS corrosion, as discriminated by the wavelet analysis. These bands correspond to the damage modes of surface vertical cracks, sliding interface cracks, opening interface cracks, and substrate deformation, respectively. In fact, the frequency band of the sliding interface crack consist of two crack types, including the crack at the YSZ/BC interface and the parallel crack in the ceramic coating caused by the compress stress in these regions. These two cracks dominate the whole failure process, and ultimately result in the spallation of coating.

(3) The failure of the TBCs attacked by CMAS mainly occurs upon the cooling period. During the failure process, interface and parallel cracks first generate in the coating. When the temperature approximately drops to $400{ }^{\circ} \mathrm{C}$, surface vertical cracks appear in the TBCs.

\section{Acknowledgments}

This work was supported by the National Natural Science Foundation of China (grant nos. 51590891, 11272275, 11472237, and 11432014).

\section{References}

[1] R.A. Miller, Thermal barrier coatings for aircraft engines: history and directions, J. Therm. Spray Technol. 6 (1997) 35-42.

[2] D.R. Clarke, M. Oechsner, N.P. Padture, Thermal-barrier coatings for more efficient gas-turbine engines, MRS Bull. 37 (2012) 891-898.

[3] D. Zhu, R.A. Miller, Development of advanced low conductivity thermal barrier coatings, Int. J. Appl. Ceram. Technol. 1 (2004) 86-94.

[4] N.P. Padture, M. Gell, E.H. Jordan, Thermal barrier coatings for gas-turbine engine applications, Science 296 (2002) 280-284.

[5] R.G. Wellman, J.R. Nicholls, A review of the erosion of thermal barrier coatings, J. Phys. D. Appl. Phys. 40 (2007) R293-R305.

[6] A. Rabiei, A. Evans, Failure mechanisms associated with the thermally grown oxide in plasma-sprayed thermal barrier coatings, Acta Mater. 48 (2000) 3963-3976.

[7] C.G. Levi, J.W. Hutchinson, M.-H. Vidal-Sétif, C.A. Johnson, Environmental degradation of thermal-barrier coatings by molten deposits, MRS Bull. 37 (2012) 932-941.

[8] X. Chen, M.Y. He, I. Spitsberg, N.A. Fleck, J.W. Hutchinson, A.G. Evans, Mechanisms governing the high temperature erosion of thermal barrier coatings, Wear 256 (2004) 735-746.

[9] J. Wu, H.-b. Guo, Y.-z. Gao, S.-k. Gong, Microstructure and thermo-physical properties of yttria stabilized zirconia coatings with CMAS deposits, J. Eur. Ceram. Soc. 31 (2011) 1881-1888.

[10] P. Mechnich, W. Braue, U. Schulz, High-temperature corrosion of EB-PVD yttria partially stabilized zirconia thermal barrier coatings with an artificial volcanic ash overlay, J. Am. Ceram. Soc. 94 (2011) 925-931.

[11] R. Wellman, G. Whitman, J.R. Nicholls, CMAS corrosion of EB PVD TBCs: Identifying the minimum level to initiate damage, Int. J. Refract. Met. Hard Mater. 28 (2010) 124-132.

[12] M.H. Vidal-Setif, N. Chellah, C. Rio, C. Sanchez, O. Lavigne, Calcium-magnesiumalumino-silicate (CMAS) degradation of EB-PVD thermal barrier coatings: characterization of CMAS damage on ex-service high pressure blade TBCs, Surf. Coat. Technol. 208 (2012) 39-45.

[13] J.M. Drexler, A.D. Gledhill, K. Shinoda, A.L. Vasiliev, K.M. Reddy, S. Sampath, N.P. Padture, Jet engine coatings for resisting volcanic ash damage, Adv. Mater. 23 (2011) 2419-2424.

[14] C. Mercer, S. Faulhaber, A. Evans, R. Darolia, A delamination mechanism for thermal barrier coatings subject to calcium-magnesium-alumino-silicate (CMAS) infiltration, Acta Mater. 53 (2005) 1029-1039.

[15] C. Zhang, C. Zhou, S. Gong, H. Li, H. Xu, Evaluation of thermal barrier coating exposed to different oxygen partial pressure environments by impedance spectroscopy, Surf. Coat. Technol. 201 (2006) 446-451.

[16] L. Yang, Y.C. Zhou, W.G. Mao, C. Lu, Real-time acoustic emission testing based on wavelet transform for the failure process of thermal barrier coatings, Appl. Phys. Lett. 93 (2008) 231906.

[17] B.W. Veal, A.P. Paulikas, P.Y. Hou, Tensile stress and creep in thermally grown oxide, Nat. Mater. 5 (2006) 349-351.

[18] R.J. Christensen, D.M. Lipkin, D.R. Clarke, K. Murphy, Nondestructive evaluation of the oxidation stresses through thermal barrier coatings using $\mathrm{Cr} 3+$ piezospectroscopy, Appl. Phys. Lett. 69 (1996) 3754.

[19] R. De, G. Ananthakrishna, Dynamics of the peel front and the nature of acoustic emission during peeling of an adhesive tape, Phys. Rev. Lett. 97 (2006) 165,503.

[20] X. Ma, M. Takemoto, Quantitative acoustic emission analysis of plasma sprayed thermal barrier coatings subjected to thermal shock tests, Mater. Sci. Eng. A 308 (2001) 101-110.

[21] X. Ma, S. Cho, M. Takemoto, Acoustic emission source analysis of plasma sprayed thermal barrier coatings during four-point bend tests, Surf. Coat. Technol. 139 (2001) 55-62.

[22] O. Trunova, P. Bednarz, R. Herzog, T. Beck, L. Singheiser, Microstructural and acoustic damage analysis and finite element stress simulation of air plasma-sprayed thermal barrier coatings under thermal cycling, Int. J. Mater. Res. 99 (2008) 1129-1135.

[23] L. Yang, Y.C. Zhou, C. Lu, Damage evolution and rupture time prediction in thermal barrier coatings subjected to cyclic heating and cooling: An acoustic emission method, Acta Mater. 59 (2011) 6519-6529.

[24] J.L. Smialek, The Chemistry of Saudi Arabian Sand: A Deposition Problem on Helicopter Turbine Airfoils, DOI, 1991.

[25] J.M. Drexler, A. Aygun, D. Li, R. Vaßen, T. Steinke, N.P. Padture, Thermal-gradient testing of thermal barrier coatings under simultaneous attack by molten glassy deposits and its mitigation, Surf. Coat. Technol. 204 (2010) 2683-2688. 
[26] A.H. Omar, P. Véronique, S. Eric, G. François, K. Jean, R. François, C. Michel, In situ high temperature oxidation analysis of Zircaloy-4 using acoustic emission coupled with thermogravimetry, J. Nucl. Mater. 461 (2015) 365-375.

[27] L. Fu, K. Khor, H. Ng, T. Teo, Non-destructive evaluation of plasma sprayed functionally graded thermal barrier coatings, Surf. Coat. Technol. 130 (2000) 233-239.

[28] W.B. Yao, C.Y. Dai, W.G. Mao, C. Lu, L. Yang, Y.C. Zhou, Acoustic emission analysis on tensile failure of air plasma-sprayed thermal barrier coatings, Surf. Coat. Technol. 206 (2012) 3803-3807.

[29] L. Yang, H.S. Kang, Y.C. Zhou, L.M. He, C. Lu, Intelligent Discrimination of Failure Modes in Thermal Barrier Coatings: Wavelet Transform and Neural Network Analysis of Acoustic Emission Signals, Exp. Mech. 55 (2014) 321-330.

[30] D.E. Newland, An introduction to random vibrations, spectral \& wavelet analysis, Courier Corporation, 2012.

[31] E.-Y. Kim, Y.-J. Lee, S.-K. Lee, Heath monitoring of a glass transfer robot in the mass production line of liquid crystal display using abnormal operating sounds based on wavelet packet transform and artificial neural network, J. Sound Vib. 331 (2012) 3412-3427.
[32] R. Khamedi, A. Fallahi, A. Refahi Oskouei, Effect of martensite phase volume fraction on acoustic emission signals using wavelet packet analysis during tensile loading of dual phase steels, Mater. Des. 31 (2010) 2752-2759.

[33] S. Krämer, S. Faulhaber, M. Chambers, D. Clarke, C. Levi, J. Hutchinson, A. Evans, Mechanisms of cracking and delamination within thick thermal barrier systems in aero-engines subject to calcium-magnesium-alumino-silicate (CMAS) penetration, Mater. Sci. Eng. A 490 (2008) 26-35.

[34] X. Fan, R. Xu, T.J. Wang, Interfacial delamination of double-ceramic-layer thermal barrier coating system, Ceram. Int. 40 (2014) 13,793-13,802.

[35] A.G. Evans, J.W. Hutchinson, The mechanics of coating delamination in thermal gradients, Surf. Coat. Technol. 201 (2007) 7905-7916.

[36] A.R. Krause, H.F. Garces, G. Dwivedi, A.L. Ortiz, S. Sampath, N.P. Padture, Calcia-magnesiaalumino-silicate (CMAS)-induced degradation and failure of air plasma sprayed yttriastabilized zirconia thermal barrier coatings, Acta Mater. 105 (2016) 355-366.

[37] G. Pujol, F. Ansart, J.-P. Bonino, A. Malié, S. Hamadi, Step-by-step investigation of degradation mechanisms induced by CMAS attack on YSZ materials for TBC applications, Surf. Coat. Technol. 237 (2013) 71-78. 